\title{
Contratos de gestão: instrumentos de ligação entre os setores do aparelho do Estado
}

\section{Marcelo de Matos Ramos}

\section{Introdução}

Neste trabalho, iremos analisar um aspecto da relação entre os chamados "setores do Estado", tal como definidos no Plano Diretor da Reforma do Estado. Em particular, estaremos preocupados em caracterizar a inter-relação entre o Núcleo Estratégico do Estado e os demais setores, procurando identificar os pontos fortes e fracos do principal instrumento que rege esta relação, qual seja, o contrato de gestão.

Entendemos que esta análise é pertinente, enquanto permite identificar possíveis fontes de dificuldades na implementação de um dos principais pontos da agenda da Reforma do Aparelho de Estado, qual seja, a segmentação do Estado e a adoção de práticas administrativas distintas que permitam maior efetividade e eficiência do aparelho de Estado, melhorando suas condições de governance.

Na próxima seção, caracterizaremos melhor os setores do Estado e a natureza da relação entre o núcleo estratégico e os demais setores, tal como se apresenta no Plano Diretor; na terceira seção faremos um breve levantamento sobre a experiência internacional e doméstica em "contratualização"; na quarta, discutiremos os fundamentos teóricos da "contratualização"; na quinta, analisaremos as principais dificuldades e fragilidades do instrumento do contrato de gestão; finalmente, na última seção, concluiremos o trabalho, aduzindo algumas recomendações e identificando rumos de pesquisa.

Especialista em políticas públicas e gestão governamental no Departamento de Carreira e Remuneração da Secretaria de Recursos Humanos do MARE 


\section{Os segmentos do Estado e seu inter-relacionamento}

A característica fundamental que preside a reforma do aparelho do Estado, ora em curso, é a adoção do modelo conceitual de segmentação do Estado em setores, que possibilita a identificação de estratégias distintas para cada um desses segmentos do Estado, em consonância com as recomendações do estado-da-arte em administração, ${ }^{1}$ tal como exposta na chamada Teoria das Configurações. Esta possibilidade de determinar padrões distintos de atuação para cada setor do Estado tem efeitos positivos para o aumento da eficácia e eficiência do aparelho de Estado como um todo. Segundo o Plano Diretor da Reforma do Estado, assim se definem os diferentes setores do Estado:

\begin{tabular}{ll}
\hline Setor do Estado & \multicolumn{1}{c}{ Atribuições } \\
\hline Núcleo estratégico & Define as leis e políticas públicas \\
& e cobra seu cumprimento, ou seja, \\
& é o setor onde as decisões estra- \\
& tégicas são tomadas. \\
\hline Atividades exclusivas & É o setor onde são prestados os \\
& serviços que só o Estado pode \\
& realizar, e onde se exerce o poder \\
& extroverso do Estado. \\
\hline Serviços não-exclusivos & É o setor onde o Estado atua si- \\
& multaneamente com outras orga- \\
& nizações públicas não-estatais e \\
& privadas; as instituições aqui não \\
& possuem poder de Estado, mas \\
& este está presente, pois a presta- \\
& ção desses serviços envolve direi- \\
& tos humanos fundamentais. \\
\hline É a área de atuação das empresas, \\
caracterizadas pelas atividades \\
econômicas voltadas para o lucro.
\end{tabular}

Cada um dos setores se distingue por possuir características específicas, tanto quanto à definição de prioridades quanto aos princípios administrativos que os regem. No núcleo estratégico, por exemplo, as decisões devem ser as melhores possíveis, portanto, o critério de efetividade é mais importante do que o de eficiência. As decisões de governo devem ser as que atendam eficazmente ao interesse nacional, e devem ser de fato cumpridas. Já nos outros setores, o critério fundamental é o de eficiência. Quanto aos princípios administrativos, devemos notar que o núcleo estratégico caracteriza-se por uma administração burocrática, que apesar do excesso de 
formalismo e da ênfase no controle de processos, tem a vantagem da segurança e da efetividade das decisões. Já os outros setores, embora em boa parte ainda sujeitos à administração burocrática, estão em transição para a chamada administração gerencial, que enfatiza o controle de resultados e a eficiência; parcela expressiva das atividades da reforma do aparelho de Estado, aliás, dizem respeito à condução dessa transição.

Os objetivos colocados pelo Plano Diretor para o núcleo estratégico englobam o aumento de sua efetividade, pela via da modernização da administração burocrática que o caracteriza, através de uma política de profissionalização do serviço público, e dotando-o da necessária capacidade gerencial para supervisionar e coordenar as atividades dos outros setores do Estado. Tal como colocado no Plano Diretor, a pedra angular do relacionamento entre o núcleo estratégico e os demais setores é um documento denominado contrato de gestão, que é um instrumento de compromisso mútuo entre as partes envolvidas. Desta forma, no que diz respeito ao contrato de gestão, caberia a cada setor do aparelho de Estado:

\begin{tabular}{ll}
\hline Setor do Estado & Relação com o contrato de gestão \\
\hline Núcleo estratégico & $\begin{array}{l}\text { Capacitar-se para definir e supervisionar } \\
\text { os contratos de gestão com os demais se- } \\
\text { tores do Estado. }\end{array}$ \\
\hline Atividades exclusivas & $\begin{array}{l}\text { Transformação das autarquias e funda- } \\
\text { ções que possuem poder de Estado em } \\
\text { agências autônomas, administradas se- } \\
\text { gundo um contrato de gestão. }\end{array}$ \\
\hline Serviços não-exclusivos & $\begin{array}{l}\text { Transformação das atuais fundações pú- } \\
\text { blicas em Organizações Sociais, }{ }^{2} \text { com au- } \\
\text { torização específica do Poder Legislativo } \\
\text { para celebrar contrato de gestão com o } \\
\text { Poder Executivo. }\end{array}$ \\
\hline Produção para o mercado & $\begin{array}{l}\text { Implantação de contratos de gestão nas } \\
\text { empresas que não puderem ser privadas. }\end{array}$ \\
\hline
\end{tabular}

Assim, do ponto de vista do Plano Diretor, o contrato de gestão aparece como instrumento fundamental na implementação da reforma do Estado, principalmente pela introdução da chamada Administração por Objetivos, aumentando a eficiência no uso dos recursos. Vamos agora, nas próximas seções, examinar a experiência internacional e nacional em contratos de gestão, explorar os fundamentos teóricos dessa forma de gestão e discutir suas eventuais fragilidades e necessárias complementações à luz da análise elaborada. 


\section{Experiência internacional e nacional em "contratualização"}

Dentre as opções de reforma do serviço público que têm se verificado em todo o mundo, cresce, em popularidade, a experimentação em torno da assim chamada "contratualização". Este movimento pode ser entendido como uma incorporação das críticas neoliberais em prol da necessidade de um comportamento empresarial autônomo em certas esferas de governo. De fato, a relação contratual estimula que as partes negociem um compromisso e assumam cada qual o seu papel sem demasiadas ambigüidades. Tipicamente, a relação contratual ocorre entre uma instância do governo central, que será o órgão supervisor do contrato, e uma agência governamental (em geral uma empresa, mas também passível de ocorrer com outras instâncias equivalentes à nossa administração autárquica e fundacional). Em geral, o contrato estipula objetivos e metas que devem ser atingidos pela agência: as autonomias a ela concedidas; os direitos e obrigações de cada parte; bem como as chamadas condicionalidades, ou seja, as situações ou cenários que instruíram a expectativa de realização e atingimento dos objetivos e metas e que se não se concretizarem extinguem a obrigação de cumprimento do contrato.

Possivelmente a primeira manifestação da chamada "contratualização" tenha ocorrido, paradoxalmente, em um país de forte tradição burocrática: em 1967 o relatório Nora recomendou, como forma de se enfrentar o alto grau de ineficiência das empresas públicas francesas, ${ }^{3}$ cada vez mais dependentes de subsídios governamentais, a "contratualização" das relações de supervisão entre Estado e empresa (para o caso francês, cf. Silva, 1994, e ENAP/SAF 1993).

Em 1969, assinavam-se os primeiros contratos de programa: ${ }^{4} \mathrm{em}$ junho, com a SNCF (ferrovias) e em dezembro com a EDF (eletricidade), seguidos pelos contratos de empresa ${ }^{5}$ (a partir de 1978) com a Air France (transporte aéreo), e a Charbonnage de France (carvão). Em 1979, foi a vez da Compagnie Générale Maritime et Financiére (navegação). Em 1982, reformou-se o sistema de planejamento na França, introduzindo assim a figura do contrato de plano, universalizando-se o procedimento de contratação para todas as empresas estatais que dependessem de alguma forma do apoio do Estado. O contrato de plano estipulava um tipo de planejamento indicativo, estabelecendo mais objetivos do que compromissos; mas o decreto de regulamentação da lei que o estabeleceu em 1982 nunca foi editado.

Em 1988, o ministro da indústria expediu às empresas por ele tuteladas um novo procedimento intitulado contrato de objetivos. Este documento tem vigência anual e sintetiza os principais pontos estratégicos e financeiros do plano estratégico da empresa. 
De forma geral, o movimento pela "contratualização" na França visa, de fato, procurar viabilizar a manutenção da presença do Estado na economia, pois este é um país de forte tradição estatal: a regra foi então "modernizar para não privatizar".

Não se pode dizer o mesmo da Grã-Bretanha, entretanto (Cf. SILVA, 1994). Este país, de forte tradição liberal até a primeira guerra, teve de passar por um forte movimento de recuperação econômica após a segunda guerra, que teve um efeito devastador sobre seu tecido industrial. Foi na reconstrução do pós-guerra que se formou o setor público empresarial no Reino Unido. Este setor público empresarial expandiu-se bastante durante as décadas de 60 e 70, principalmente devido às ações dos sucessivos governos trabalhistas. O modelo, entretanto, exauriu-se ao final da década de 70, e tornou-se patente a deterioração dos serviços públicos; além disso o planejamento governamental inglês sofreu na época sérios reveses, com os objetivos de reorganização e racionalização industrial e de uma política de renda eficaz frustrados; o padrão de vida da população britânica caiu vis à vis a dos países europeus do continente.

A saída encontrada pelo governo conservador de Tatcher, eleita em 1979, foi a privatização. Numa primeira fase privatizaram-se as empresas competitivas; na segunda fase vieram as privatizações das estatais de infra-estrutura, colocando-se a questão dos monopólios naturais e da necessidade de elaborar-se mecanismos regulatórios eficazes. Portanto, não houve na Grã-Bretanha uma experiência de contratos de gestão com empresas estatais no setor produtivo.

No âmbito da administração pública, entretanto, o movimento da “contratualização" vem ganhando espaço desde 1988, com o programa Next Steps (Cf. JENKINS 1996), cujo objetivo foi o de reduzir a administração centralizada; de fato, no início de 1996 cerca de $65 \%$ da força de trabalho na administração pública britânica localizava-se nas agências que têm sistemas gerenciais separados da administração pública centralizada, gerenciando seu próprio pessoal e recursos e sendo supervisionadas pelo órgão supervisor dentro das condições estabelecidas num documento denominado "framework document".

De forma geral, pode-se caracterizar o movimento pela “contratualização", no caso britânico, como um modelo em três dimensões (Cf. ABRUCIO, 1996):

a) a extensão das relações contratuais no fornecimento de serviços públicos entre o setor público, o setor privado e o voluntário/não-lucrativo, criando uma nova estrutura de pluralismo institucional, contraposta ao antigo modelo de monopólio estatal;

b) extensão das relações contratuais para dentro do setor público, envolvendo descentralização, delegação e mecanismos de "quasi market";

c) desenvolvimento de contratos de qualidade entre os provedores de serviços e consumidores/clientes. 
Finalmente, para terminar este levantamento sobre a experiência internacional, Shirley (1996), classificando os tipos de contratos entre três categorias, faz um excelente levantamento sobre a utilização de contratos de gestão em países em desenvolvimento, chegando aos seguintes números: mais de 550 contratos de desempenho em 32 países, que definem relações entre o governo e administradores públicos, e mais de 100.000 destes contratos só na China; 202 contratos de gestão em 49 países, que definem a relação entre o governo e um empresa privada contratada para administrar uma empresa estatal; e sete contratos de regulação no setor de telecomunicações; este último tipo de contrato define a relação entre o governo e um monopólio regulado.

Em termos da experiência brasileira, as mais dignas de nota são as do Estado de São Paulo e as levadas a cabo no âmbito federal (Cf. de ANDRÉ, 1994).

A experiência de contratos de gestão em São Paulo vem desde o final da gestão Montoro em 1986, de quando datam os estudos piloto para a avaliação de desempenho nas empresas estatais paulistas. Os primeiros contratos de gestão foram celebrados a partir de 1991, com todas as 25 empresas públicas. Entretanto, a natureza destes contratos foi muito diversificada, dada a heterogeneidade das empresas em termos de desenvolvimento gerencial; além do mais, o governo do estado até hoje não concedeu as autonomias de gestão inicialmente previstas. Inicialmente com previsão de vigência por um ano, os primeiros contratos (exercício 1992) não conseguiram, freqüentemente, estabelecer uma especificação adequada dos compromissos; os do exercício de 1993 já evoluíram sobre os precedentes, dando maior relevância à eficiência e à qualidade. Os de 1994 avançaram ainda mais, fortalecendo o planejamento estratégico de médio prazo e ampliando o horizonte de planejamento pela extensão do prazo contratual para dois anos. O estado de São Paulo também realizou experimentos com contratos de gestão para a administração pública não-empresarial, neste caso, sem indicadores de desempenho para a dimensão da eficiência, estipulando apenas metas de eficácia e volume de serviço.

A experiência federal tem início com o decreto no 137 de 27 de maio de 1991, que instituiu o Programa de Gestão das Empresas Estatais (PGE). O programa consiste na fixação de um conjunto de diretrizes gerais e setoriais destinadas a compatibilizar a gestão das estatais com a política econômica e com o planejamento setorial, bem como promover a sua modernização. Estas diretrizes são fixadas pelo Comitê de Coordenação das Empresas Estatais (CCE), órgão colegiado que tem como membros permanentes o titular da pasta do Planejamento (que é o presidente), o da Fazenda e seus respectivos secretários-executivos. Participam, também, os ministros de Estado e secretários-executivos dos ministérios a que forem vinculadas as empresas cujos interesses estiverem em 
pauta. A secretaria executiva do CCE é a SEST, Secretaria de Coordenação e Controle das Empresas Estatais, subordinada ao Ministério do Planejamento. Ao CCE compete:

- fixar as diretrizes do PGE;

- aprovar propostas das empresas estatais sobre diversos tópicos de seu gerenciamento;

- aprovar e supervisionar os contratos de gestão das empresas estatais;

- acompanhar o desempenho das empresas e relatar ao Presidente da República.

A estrutura genérica dos contratos de gestão com as empresas estatais federais inclui uma descrição do contexto macroeconômico em que a empresa opera e os cenários previstos para sua ação futura (também chamados "condicionalidades"), o diagnóstico da empresa, a determinação das partes contratantes, o objeto geral do contrato, os objetivos, metas e indicadores de desempenho a serem acompanhados, e as isenções de autorizações prévias e outras normas de controle (as chamadas "autonomias").

A primeira empresa a firmar um contrato de gestão foi a Companhia Vale do Rio Doce, em 1992. A segunda foi a Petrobrás, em 1994. Negociase, atualmente, contratos de gestão para outras empresas tais como a Telebrás, os Correios, o BNDES, a Finep, a Eletrobrás, entre outras.

Há ainda a idéia de se celebrar outros tipos de acordos distintos dos contratos de gestão, os chamados "Acordos de Desempenho" ou "Convênios de Desempenho", que são instrumentos distintos que visam atingir também a administração por objetivos; sua diferenciação dos contratos de gestão comuns devem-se às dificuldades de se expandir a experiência dos contratos de gestão (com suas respectivas concessões de autonomias) para todo o setor estatal. Assim é que o Ministério de Minas e Energia já vem utilizando instrumentos similares para suas empresas desde 1991, e o Ministério dos Transportes firmou com a RFFSA, a CBTU, a Cia. Docas e outras os "compromissos de resultados", instrumentos de concepção bem semelhante aos anteriormente referidos.

Mais recentemente, o Plano Diretor da Reforma do Estado estipulou a extensão dos contratos de gestão às chamadas Agências Executivas e Organizações Sociais. Até esta data (julho de 1997), porém, nenhum contrato foi firmado, embora algumas entidades estejam em adiantado estado de negociação.

\section{Fundamentos teóricos da "contratualização"}

Segundo Melo (1996), pode-se discernir entre a multiplicidade de propostas de reorganização burocrática duas variantes de prescrições, cada uma identificada com uma dada tradição disciplinar. Uma delas é a tradição advinda da administração pública, que enfatiza 
aspectos relacionados à identidade, socialização, sistema de crenças e capacitação da burocracia pública. A outra corresponde à tradição disciplinar da economia, onde a ênfase recai sobre os aspectos relativos à estrutura de incentivos com que se deparam os atores em uma organização burocrática, analisados a partir de uma perspectiva de indivíduos racionais maximizadores de seus interesses e utilidades.

As mais fecundas contribuições dessa segunda tradição disciplinar provêm do campo conhecido como neo-institucionalismo econômico, ${ }^{6}$ que adota o paradigma contratualista no exame das relações entre indivíduos, as relações entre indivíduos ou grupos e as instituições, e as próprias instituições. Nesse paradigma as transações podem ser modeladas como uma situação que envolve dois atores, um chamado agente e o outro chamado principal. ${ }^{7}$ Esta situação é tipicamente a que acontece quando há uma separação entre controle e propriedade, ou seja, quando há uma delegação de autoridade; por exemplo, quando o agente é um empregado contratado por um empregador (o principal), para realizar uma tarefa pré-especificada. $\mathrm{O}$ problema contemplado então pela teoria do agente principal tem a ver com a existência de informação assimétrica entre agente e principal, pois o custo do controle total para o principal é tal que não valeria a pena contratar o agente. Por outro lado, o agente, sendo o único que detém todas as informações sobre seu próprio desempenho, pode utilizá-la de forma oportunista.

A teoria agente-principal assume ainda mais relevância na discussão sobre descentralização, tanto nas questões referentes ao federalismo (ou seja, envolvendo as esferas de poderes subnacionais) quanto na descentralização intra-organizacional em agências ou setores do governo. Nesse caso, há justificativas de ordem econômica para a descentralização, relacionadas aos ganhos em termos de eficiência alocativa. Admite-se que a descentralização permite ganhos em termos de maior heterogeneidade e variabilidade na provisão de serviços, maiores possibilidades de geração de inovações e aprendizado organizacional devido à competição intra-organizacional entre unidades administrativas.

Ora, claro está que, para os nossos propósitos neste texto, podemos caracterizar a burocracia descentralizada (ou seja, aquela que está na agência autônoma ou empresa estatal objeto do contrato de gestão) como sendo o agente, e a burocracia do órgão supervisor do contrato de gestão como sendo o principal. ${ }^{8}$ Nesse caso, o oportunismo do agente pode se fazer sentir no momento em que ele não aplica todo o esforço que poderia despender para a satisfação das necessidades do principal, a partir do momento em que esse esforço gera uma desutilidade para o agente. Tratase então basicamente de uma situação de conflito de interesses, ou para usar um termo mais técnico, de um trade-off entre as funções objetivo do agente e do principal. Ora, a magnitude do esforço é inobservável pelo principal, pois o custo da informação perfeita pode facilmente superar a 
utilidade, para o principal, de contratar o agente; essa é a origem do fenômeno da informação assimétrica.

As soluções prescritas pela literatura sobre o problema agenteprincipal envolvem em geral o desenvolvimento de uma estrutura de incentivos que permita uma harmonização maior entre os objetivos do principal e os do agente, ou seja, permita que as funções objetivo de cada um reforcem-se mutuamente. Na próxima seção, arrolaremos as principais críticas e deficiências identificadas nos contratos de gestão e com base nas contribuições da teoria agente-principal (quando couber) faremos algumas recomendações sobre as formas de debelar as dificuldades encontradas na implementação de contratos de gestão. Faremos também algumas considerações sobre as críticas aos contratos de gestão que provêm de campos que estão fora do alcance das prescrições da teoria agenteprincipal e da tradição disciplinar da economia como um todo; em particular, discutiremos as relações entre o Núcleo Estratégico do Estado e os demais setores em termos das possibilidades de aprendizado organizacional e do impacto da "contratualização" sobre os processos de aprendizado.

\section{As críticas e as deficiências dos contratos de gestão}

Vamos analisar primeiramente as dificuldades apontadas na utilização dos contratos de gestão na França. SILVA (1994) identifica dois pontos críticos, a saber:

a) compatibilização entre os objetivos de "serviço público" e os da empresa. Em particular, há muita divergência em relação ao valor das transferências compensatórias feitas como contrapartida a custos extras incorridos pela empresa ao prover serviços economicamente injustificáveis, mas que têm significação social.

b) a definição dos fluxos financeiros entre empresa e Tesouro, principalmente no tocante às principais fontes de recursos para investimentos: recursos próprios, endividamento e capitalização. No caso dos recursos próprios, há grande influência da atuação do governo na administração das tarifas (importante na política antiinflacionária). $\mathrm{O}$ endividamento também apresenta problemas, pois o governo procura aliviar os encargos financeiros do endividamento externo e interno. A capitalização, ou seja, inversão de recursos do Tesouro nas empresas, necessária quando as metas de investimento excedem aos recursos da empresa, também é um foco de tensão.

Há outros problemas. Por exemplo, as empresas estatais demonstram tendência a subavaliar suas potencialidades, de forma a tornar as metas, principalmente as de produtividade, mais fáceis de serem cumpridas. Também não tem sido fácil implementar formas de gratificações de desempenho, devido 
a resistências sindicais. Não se deve também ceder à tendência de construir sistemas de acompanhamento, controle e avaliação de desempenho que tenham pretensões de extrair informação total, o que leva a um custo proibitivo; tais sistemas devem servir apenas como "feedback" para a avaliação das políticas, proporcionando melhores condições para se negociar os próximos contratos, bem como para orientar o sistema de incentivos.

O balanço geral da "contratualização" na França é positivo, embora apenas a Air France tenha melhorado nitidamente seus resultados financeiros; mas o impacto de variáveis ambientais adversas tornou os contratos de gestão, em sua maioria, irrelevantes. Apesar disso os gestores das empresas e os supervisores governamentais consideram a experiência um sucesso, basicamente devido a maior transparência adquirida pelas operações e pelos resultados. Um outro benefício, este de natureza política, foi que a "contratualização" tem servido de base para a estratégia de reforma da administração pública direta na França, sob a égide da "responsabilização e autonomia gerencial”.

Quanto à "contratualização" na Grã-Bretanha, segundo JENKINS (1996), o programa Next Steps teve efeitos substanciais sobre a estrutura da administração pública e também influenciou a auto-imagem desta última, tornando-a menos resistente à mudança; segundo ela, de modo geral, os serviços melhoraram em velocidade, eficiência e confiabilidade.

Ainda no contexto britânico, Abrucio (1996) coloca outros problemas. Um deles é o do relacionamento entre a agência e o Ministério das Finanças: em um contexto de escassez de recursos públicos, onde a lógica das agências é a do output e a do Ministério é a do input financeiro, há um conflito de interesses onde via de regra o vencedor é o ministro das Finanças. Outra crítica dirigida por Abrucio é referente à distinção entre cidadão e consumidor; se a agência preocupa-se apenas com os seus clientes ou consumidores, facilmente estes podem organizar-se em grupos de interesse que irão procurar influenciar a agência em benefício próprio e não em nome do interesse público.

O trabalho de Shirley sobre a "contratualização" nos países em desenvolvimento não apóia a tese de que tais contratos contribuam na melhoria do desempenho das empresas estatais. Como principais dificuldades, Shirley identifica a manobra dos executivos das empresas em construir metas fáceis de atingir, explorando o despreparo dos funcionários dos órgãos supervisores; além do mais, como as empresas estatais abrigam a elite do serviço público, os funcionários dos órgãos supervisores sentem-se desmotivados e desprestigiados diante daqueles. Também detectaram-se deficiências nos sistemas que estipulavam recompensas e punições, de parte a parte; o estudo enfatiza a extrema dificuldade de obrigar o Estado a cumprir com sua parte no contrato. Curiosamente, os contratos, quando realizados com empresas privadas, são em geral muito mais eficazes; a autora atribui esta diferença ao fato de que as forças que motivam e mantêm 
a propriedade estatal colocam obstáculos ao funcionamento de mecanismos de mercado nas empresas estatais (visto que estas poderiam se beneficiar, teoricamente, do mesmo tratamento dado pelo governo às empresas privadas contratadas).

As principais dificuldades encontradas para o sucesso dos contratos de gestão em São Paulo, no caso das empresas estatais, são os seguintes, segundo ANDRÉ (1994):

a) falta de diretrizes de governo adequadas;

b) dificuldade de associar objetivos e metas datadas e quantificáveis ao orçamento anual;

c) desarticulação entre orçamento anual e execução financeira;

d) falta de um programa de reestruturação organizacional;

e) insuficiente capacitação do pessoal para o planejamento e a gestão;

f) não-envolvimento da Secretaria de Fazenda.

Ainda segundo a mesma autora, no caso das entidades da administração direta, autárquica e fundacional, surgem ainda os seguintes problemas: a dificuldade de identificar claramente a missão do órgão e os clientes, e a inexistência de sistemas de acompanhamento, controle e avaliação.

Merlo (1995) e Robles (1994) concluem que de forma geral os contratos de gestão em São Paulo não atingiram seu objetivo, devido basicamente a falhas na negociação do contrato (por problemas de informação assimétrica, despreparo do órgão supervisor e inexistência de um objetivo agregador); problemas na concessão das autonomias às empresas, e problemas conceituais no acompanhamento e na aferição do desempenho das empresas.

Finalmente, quanto à experiência nacional, podemos dizer o seguinte: o contrato de gestão com a CVRD (Companhia Vale do Rio Doce) tem sido um sucesso, principalmente no tocante à autonomia concedida quanto à gestão de pessoal, fixação de preços e desburocratização na prestação de contas; um grande empecilho tem sido a dificuldade de implementar a autonomia de compra de materiais, equipamentos e serviços, tolhida ainda pela Lei 8.666.

No caso da Petrobrás, partes do contrato ainda estão em negociação. De forma geral, ele é semelhante ao da CVRD, mas verifica-se uma menor liberdade no tocante às autonomias, bem como menos contrapartidas da parte do Estado.

Faremos agora algumas considerações sobre as dificuldades colocadas.

Primeiramente, há o problema da negociação do contrato. Esse é um problema sobre o qual a teoria do agente principal se cala, pois ela apenas analisa os problemas que surgem no cumprimento do contrato, e não os problemas intrínsecos à sua elaboração. Está claro que boa parte da solução aqui não pode vir da tradição disciplinar da economia, mas sim da tradição disciplinar da administração pública. Em particular, a capacitação técnica das partes é fator determinante na elaboração de 
contratos, principalmente quanto a qualificação do pessoal do órgão supervisor (justamente aquele que, em geral, está na parte prejudicada do problema da informação assimétrica). Um outro problema que pode ser adequadamente tratado ao se preparar uma negociação adequada do contrato é envolver de início todos os atores interessados, como, por exemplo, os órgãos do Estado responsáveis pelas finanças; essa é a melhor maneira de evitar que o Estado venha a falhar na provisão das suas contrapartidas.

O sistema de acompanhamento deve ser projetado para possibilitar a avaliação da política global, bem como para fornecer subsídios ao ajuste do sistema de incentivos, peça fundamental na harmonização dos interesses do agente e do principal.

A teoria do agente-principal tem algo a dizer sobre o problema do controle social das agências. Como vimos, uma perspectiva possível na ótica agente principal é quando a burocracia descentralizada é o agente, e a sociedade civil é, diretamente, o principal. Esta instância de controle suplementar pode ser utilizada para reforçar o incentivo do agente (a burocracia descentralizada) em buscar atingir os objetivos dos seus dois principais: a população e a burocracia supervisora, quando o interesse desses dois for o mesmo, isto é, o interesse público.

Nessa hipótese, a questão do controle social toma a seguinte forma: quem deve participar dessa instância de controle suplementar? Esse problema é formalmente similar ao que ocorre na empresa privada, principalmente nas grandes corporações. KosNIK (1987) coloca esse problema do ponto de vista do agente-principal, analisando a composição dos conselhos de administração das grandes corporações. Em tese, os conselhos devem agir em prol da defesa dos interesses dos acionistas. Entretanto, sabe-se que ocorrem situações de hegemonia da gerência: por vezes os executivos conseguem utilizar a corporação em benefício próprio, por omissão, negligência ou mesmo cooptação do conselho. Em seu artigo, Kosnik conclui que os seguintes fatores são importantes para evitar a cooptação do Conselho: a proporção de conselheiros estranhos à empresa (por exemplo, sem ligações familiares ou de negócios com os administradores), a proporção de conselheiros com experiência em gestão, e a proporção de conselheiros com interesses contratuais no bom funcionamento da instituição (ou melhor, em nosso caso específico: conselheiros cujo interesse seja harmônico com o interesse público). Uma condição importante, portanto, é que a instância de controle social seja escolhida de forma independente, e sem a participação da administração (ou seja, da burocracia supervisada). Esse é um ponto ainda não totalmente esclarecido, por exemplo, na proposta do Plano Diretor da Reforma do Estado, no tocante aos contratos de gestão a serem selados com as Agências Executivas e Organizações Sociais.

Eventualmente, pode ser que o conjunto de representantes da sociedade civil que preenche estas condições seja um conjunto vazio. Em todo caso, a questão do controle social é uma questão de aprendizado, e 
sempre há um custo associado ao aprendizado (que é o custo de errar).

A sociedade deve decidir, portanto, se está disposta a pagar o preço desse aprendizado. Devemos notar, entretanto, que o período aberto pelo qual passamos, onde as liberdades democráticas estão garantidas e há liberdade de opinião e de imprensa, facilita a contenção do custo desse aprendizado, à medida que eventuais erros possam ter maior transparência e serem mais prontamente sanados. ${ }^{9}$

A questão da definição da estrutura de incentivos é fundamental. Trata-se basicamente de projetar o sistema de incentivos mais adequado à tarefa de obter o alinhamento entre os interesses do agente e os do principal. Em geral, os esquemas de incentivo giram em torno de uma gratificação de desempenho sobre algum indicador, tal como produtividade, volume de produção, lucros, valorização das ações em bolsa, e outros. ${ }^{10}$ A definição do indicador, entretanto, não está livre de problemas. Por exemplo, atualmente, nos Estados Unidos, as gratificações aos executivos principais baseadas em valorização nas ações em bolsa tem sido duramente criticada, com base em que, para atingir esta valorização, a estratégia usada tem sido a do downsizing, ${ }^{11}$ que valoriza a empresa no curto prazo (pois a perspectiva de redução de custos é atraente aos investidores em bolsa) mas pode ser bastante prejudicial ao desempenho da empresa no curto prazo (Cf. Drucker (1996) e Hamel e Prahalad (1995)).

No caso onde há de se levar em conta as condições específicas da prestação de um serviço público, em que não existe a dimensão do lucro, devemo-nos preocupar em determinar se o incentivo monetário aos executivos virá do Tesouro nacional ou de receitas próprias; além disso o indicador de desempenho que servirá de base para a compensação monetária precisa ser muito bem definido. Um exemplo esclarecerá a questão.

O INPI - Instituto Nacional da Propriedade Industrial é uma das autarquias candidatas a se transformar em agência executiva. Este órgão é o responsável pelo registro das atividades referentes à propriedade industrial no Brasil, a saber: registro de marcas, depósito de patentes e averbação de contratos de transferência de tecnologia. Este órgão apresenta como seu problema central, atualmente, a lentidão no processo de concessão do registro de patentes; enquanto o prazo de validade de uma patente vai de 10 a 15 anos, desde a data de registro, o INPI está atualmente demorando cerca de cinco anos para conceder a carta patente. Uma das idéias para agilizar este processamento é a de estipular um adicional de produtividade para os funcionários, dependente do número de patentes processadas.

Ora, o sistema de propriedade industrial funda-se sobre um compromisso entre o Estado e o inventor, pelo qual o Estado assegura ao inventor o monopólio temporário para a exploração de sua invenção; em contrapartida, o inventor se compromete a tornar públicos os conhecimentos 
tecnológicos que tornam possível este avanço da técnica. Esta publicização se dá pela confecção de um "documento de patente" que descreve o invento, e que é tornado disponível no banco de patentes do INPI. A rationale do sistema é promover o estímulo à atividade inventiva, tanto ao assegurar o retorno do investimento do inventor (pelo monopólio temporário), quanto pela possibilidade de expansão do estado-da-técnica a partir da consulta ao material disponível no banco de patentes por outros inventores.

Um sistema de incentivos mal projetado, que estimule a concessão indiscriminada de patentes, significará a proliferação de monopólios, muitas vezes ilegítimos (se a patente for mal processada, isto é, se se conceder um monopólio a uma demanda que não é de fato uma invenção). Assim, há de se melhorar a qualidade deste indicador, ou até mesmo criar uma outra agência (externa ao INPI) cujo incentivo seja justamente o de conseguir a nulidade do maior número possível de patentes (via oposições e contestações diversas, desde que tecnicamente embasadas. $)^{12}$

Finalmente, devemos considerar os aspectos da "contratualização" referentes aos processos de aprendizado que levam ao "aprendizado organizacional”. Certos críticos tendem a afirmar (Cf. RANSON e STEWART, 1994) que a própria forma contratual em si pode ser um grave empecilho para a flexibilidade, uma vez que os termos do contrato, uma vez definidos, geram uma focalização sobre o contrato e não sobre a realidade, prejudicando o "aprendizado organizacional.

Nevis et alli (1995) definem em poucas palavras "aprendizado organizacional" como a capacidade, ou os processos, dentro de uma organização, que visam manter ou melhorar a performance, a partir da experiência. Segundo eles, o aprendizado organizacional é um fenômeno sistêmico, porque ele permanece na organização mesmo quando os indivíduos são trocados.

Para os autores, as bases de conhecimento da organização é que vão possibilitar a construção de capacitações que se traduzirão em habilidades organizacionais. ${ }^{13}$ Daí o papel fundamental dos fatores que, segundo a terminologia emprestada de Huber (cf. HuBER 1991), promoverão a aquisição do conhecimento, a disseminação do conhecimento e a utilização do conhecimento.

Como vimos na análise pregressa, um dos grandes entraves à "contratualização" apontados pelas diversas experiências é a insuficiência de capacitação dos órgãos supervisores em elaborar e monitorar o contrato de gestão. Evidentemente, a questão da gestão efetiva das bases de conhecimento da organização aqui se coloca de forma aguda; essa gestão diz respeito não apenas aos conhecimentos técnicos, específicos de cada instituição administrada (saúde, educação, petróleo, mineração etc.) como também aos conhecimentos tácitos sobre a própria relação contratual em si. Uma prova, aliás, dessa ineficiente gestão do conhecimento é a repetição, em escala federal, de alguns problemas já experimentados em escala estadual (no estado de São Paulo). 
Eis a seguir alguns pontos que devem ser considerados ao se abordar as organizações como "sistemas de aprendizagem":

a) O conhecimento é algo possuído pelas pessoas ou está sob a forma de "know-how" publicamente acessível?

b) Os métodos de compartilhamento do conhecimento são formais, prescritos, gerais ou por meios informais?

c) O aprendizado é incremental/corretivo ou transformativo/radical?

d) Estimula-se o desenvolvimento de habilidades individuais ou habilidades do grupo ou time?

Nevis também indica os seguintes fatores como "facilitantes" do aprendizado organizacional:

\begin{tabular}{|c|c|}
\hline 1. Imperativo de varredura & $\begin{array}{l}\text { Coleta de informações sobre condições e práticas fora da } \\
\text { unidade; preempção do ambiente; curiosidade sobre o } \\
\text { ambiente externo em contraste com o ambiente interno. }\end{array}$ \\
\hline 2. "Gap" de performance & $\begin{array}{l}\text { Percepção compartilhada da existência de um gap en- } \\
\text { tre o estado atual e o desejado de determinada perfor- } \\
\text { mance; problemas de performance vistos como opor- } \\
\text { tunidades para o aprendizado. }\end{array}$ \\
\hline 3. Preocupação com a medida & $\begin{array}{l}\text { Considerável esforço em definir e medir fatores-chave } \\
\text { quando aventurando-se em áreas novas; busca de me- } \\
\text { didas específicas e quantificáveis; discussão da métrica } \\
\text { como uma atividade de aprendizado. }\end{array}$ \\
\hline 4. Mentalidade experimental & $\begin{array}{l}\text { Tentar coisas novas; curiosidade sobre como as coisas } \\
\text { funcionam; habilidade de experimentar; falhas são acei- } \\
\text { tas e não punidas; mudanças nos processos de traba- } \\
\text { lho, políticas e estruturas são uma série contínua de } \\
\text { oportunidades de aprendizado. }\end{array}$ \\
\hline $\begin{array}{l}\text { 5. Clima organizacional aberto } \\
\text { ou arejado }\end{array}$ & $\begin{array}{l}\text { Informação facilmente acessível; comunicações dentro } \\
\text { da organização facilitadas; problemas/erros/lições são } \\
\text { compartilhados e não escondidos; debate e conflito } \\
\text { são formas aceitáveis de se resolver problemas. }\end{array}$ \\
\hline 6. Educação contínua & $\begin{array}{l}\text { Compromisso perene com a educação em todos os ní- } \\
\text { níveis da organização; apoio total ao desenvolvimento } \\
\text { e crescimento de todos os membros da organização. }\end{array}$ \\
\hline 7. Variedade operacional & $\begin{array}{l}\text { Variedade de métodos, procedimentos e sistemas; valo- } \\
\text { rização da diversidade; definição das competências va- } \\
\text { lorizadas é pluralística e não uniforme. }\end{array}$ \\
\hline 8. Advogados múltiplos & $\begin{array}{l}\text { Novas idéias e métodos podem ser propostos por em- } \\
\text { pregados em todos os níveis; mais de um "champion". }\end{array}$ \\
\hline 9. Envolvimento da liderança & $\begin{array}{l}\text { Os líderes articulam a visão, estão engajados na sua } \\
\text { implementação; interagem freqüentemente com os } \\
\text { membros da organização, envolvem-se ativamente nos } \\
\text { programas educacionais. }\end{array}$ \\
\hline 10. Perspectiva sistêmica & $\begin{array}{l}\text { Interdependência das unidades organizacionais; proble- } \\
\text { mas e soluções vistos em termos de relacionamentos } \\
\text { sistêmicos entre processos; conexão entre as necessida- } \\
\text { des e metas da unidade e as da organização. }\end{array}$ \\
\hline
\end{tabular}


Mais uma vez, portanto, vemos que a implementação com êxito do instrumento do contrato de gestão depende, além dos imperativos apontados pela tradição disciplinar da economia, de certos cuidados no âmbito da tradição disciplinar da administração pública, em particular da gestão do conhecimento e dos sistemas de aprendizado. Estes cuidados devem ser mais enfatizados no que diz respeito ao núcleo estratégico do Estado, não só por este localizar-se, por definição, do lado mais prejudicado do ponto de vista da assimetria de informações, quanto pela dificuldade inerente de se administrar eficientemente as bases de conhecimento e os sistemas de aprendizado no contexto de uma administração burocrática.

\section{Conclusão}

Certamente a questão da inter-relação entre o núcleo estratégico do Estado e os demais setores do aparelho do Estado comporta inúmeras outras questões além das que contemplamos aqui. ${ }^{14}$ Restringimo-nos, porém, neste trabalho, por uma questão de tempo e de foco, em apenas a analisar o principal instrumento que governa esta relação, qual seja, o contrato de gestão. Nossas recomendações, no âmbito puramente da tradição disciplinar da economia, referem-se à necessidade de se adotar, quando possível, as medidas sugeridas pela teoria do agente-principal a fim de enfrentar os problemas da adequação da estrutura de incentivos e da efetivação do controle social. Além disso, deve-se procurar levar em conta também os aspectos que transcendem a tradição disciplinar da economia e já invadem a tradição disciplinar da administração pública, em particular no que se refere à negociação dos instrumentos contratuais e à gestão do conhecimento e dos sistemas de aprendizado na administração pública, com ênfase na capacitação do núcleo estratégico. 
1 Vide, por exemplo, Mintzberg, 1995.

2 Segundo o Plano Diretor de Reforma do Estado, o objetivo aqui é transferir para o setor público não-estatal os serviços não-exclusivos, através de um programa de "publicização", transformando as atuais fundações públicas em Organizações Sociais, ou seja, em entidades de direito privado, sem fins lucrativos, que tenham autorização específica do Poder Legislativo para celebrar contrato de gestão com o Poder Executivo e assim ter direito a dotação orçamentária. Esta inovação em matéria de gestão visa conseguir uma maior autonomia e uma conseqüente maior responsabilidade para os dirigentes desses serviços, bem como possibilitar um controle social direto dos serviços por parte da sociedade através de sua participação, via representantes, nos conselhos de administração destas Organizações Sociais.

3 Importante frisar aqui o alto grau de importância das empresas estatais na França, país onde o segmento empresarial público desenvolveu-se e expandiu-se sob o regime de tutela direta; e com uma história onde extensos períodos de governos socialistas, com uma visão estratégica centrada no Estado (o "front populaire" na década de 30 e o governo Mitterrand nos anos 80), expandiram o sistema empresarial estatal sob a forma jurídica de "empresa pública", instrumento privilegiado para o desenvolvimento nacional francês.

4 Os contratos de programa, em geral, descreviam objetivos ligados ao equilíbrio orçamentário, produtividade global dos equipamentos e dos recursos humanos, aumento de recursos próprios, rentabilidade financeira, supressão de certos serviços nãorentáveis e racionalizações diversas.

5 Os contratos de empresa retomavam a idéia básica dos contratos de programa, com a diferença de explicitarem a definição de cada um dos objetivos não somente por resultados gerais, mas com a produtividade de cada fator de produção em função das diversas condições econômicas externas.

6 Esta tradição frutifica também na chamada Economia Organizacional, com contribuições teóricas relevantes nos campos da economia dos custos de transação, economia da regulação, e finalmente, a própria discussão sobre privatização.

7 Essa é a formulação básica da chamada Teoria Agente-Principal, também chamada Teoria do Agenciamento ou como é mais conhecida em inglês, "Agency Theory".

8 Naturalmente é fácil notar que existem outras relações possíveis, dependendo do nosso ponto de vista. Por exemplo, a burocracia que administra os contratos de gestão é a responsável pela definição e condução das políticas públicas pode, por sua vez, ser encarada como a agente; nesse caso, o principal é a classe política (estamos nos referindo aqui ao modelo de democracias representativas onde o político eleito é dono de um mandato para implementar o programa político com o qual se elegeu). Por outro lado, a própria classe política pode ser encarada como o agente, e o eleitorado como o principal. De uma forma muito especial, numa situação de maior controle social direto, a burocracia descentralizada pode ser o agente e a população, representada por entidades da sociedade civil, ou associações de usuários - qualquer instância de controle social que passe por fora da democracia representativa — pode ser o principal. Voltaremos a esse tema na próxima seção; para uma discussão mais detalhada, veja PRZEWORSKI (1996). 
9 Não custa lembrar aqui o processo da chegada ao poder e do impeachment do presidente Collor. Não sabemos o quanto o processo custou ao País, e nem temos uma estimativa razoável do aprendizado embutido no processo; há, entretanto, uma percepção difusa de que o processo democrático brasileiro está se aperfeiçoando.

10 Cf. Pindyck (1994).

11 O termo inglês "downsizing" é utilizado para denominar processos reorganizacionais que via de regra implicam a demissão de um grande número de funcionários, reduzindo níveis hierárquicos e racionalizando processos.

12 Até pouco tempo, sem nenhum mandato específico e por uma questão puramente "residual" da época do extremado zelo pela soberania nacional, a Petrobrás desempenhava este papel, pelo menos no campo das tecnologias relacionadas ao petróleo.

13 Ou seja, na terminologia moderna de administração, essas bases de conhecimento seriam então as "competências" da organização. Esses conhecimentos podem ser formais e explícitos ou tácitos e implícitos.

${ }^{14}$ Por exemplo, a questão política. 


\section{Referências bibliográficas}

Abrucio, F. L. "O impacto do modelo gerencial na administração pública: um breve estudo sobre a experiência internacional recente". mimeo, 1996.

De ANDRÉ, M. A. "Contratos de gestão: texto básico para subsídio às discussões sobre a reforma do Estado". Convênio IBAM/IPEA/ENAP. Rio de Janeiro, IBAM, 1994.

DRUCKER, P. "The relentless contrarian”. Entrevista à Wired Magazine, agosto de 1996. Hamel, G.; Prahalad, C. K. "Competindo pelo futuro". Campus, Rio de Janeiro, 1995. Huber, G. "Organizational Learning: the Contributing Processes and Literature". Organizational Science 2, 1991.

Jenkins, K. "Civil Service Reform in the United Kingdom". In: A reforma do Estado na América Latina e no Caribe: rumo a uma administração pública gerencial. MARE/ BID/ONU, Brasília, 1996.

KosNik, R. D. "Greenmail: a study of board performance in corporate governance". Administrative Science Quarterly 32, 1987.

Melo, M. A. "Governance e reforma do Estado: o paradigma agente x principal". Revista do Serviço Público, v. 120 n. 1, ENAP, jan.-abr. 1996.

Merlo, E. M. "Contrato de Gestão: análise da experiência paulista em empresas públicas do setor energético". Dissertação de Mestrado, FEA/USP, 1995.

MintZBerg, H. "Criando organizações eficazes: estruturas em cinco configurações". Atlas, São Paulo, 1995.

Nevis, E. C., DiBella, A. J., Gould, J. M. "Understanding Organizations as Learning Systems", Sloan Management Review, Winter 1995.

Presidência da República/CÂmara da Reforma do Estado. "Plano Diretor da Reforma do Estado". Brasília 1995.

Pindyck, R. S.; Rubinfeld, D. L. "Microeconomia”. Makron Books, São Paulo, 1994.

Przeworski, A. "On the design of the State: a principal-agent perspective”. In: A reforma do Estado na América Latina e no Caribe: rumo a uma administração pública gerencial. MARE/BID/ONU, Brasília 1996.

Ranson, S.; Stewart, J. "Management for the Public Domain: Enabling the Learning Society". St. Martin's Press, 1994.

Robles, L. T. "Considerações sobre a gestão de empresas estatais e o instrumento do contrato de gestão". Dissertação de Mestrado, FEA/USP, 1994.

SHIRLEY, M. M. "Son los contratos com las empresas un instrumento eficaz ?". Finanzas \& Desarrollo, septiembre 1996.

SiLVA, C. E. S. "Transformações nas formas de controle sobre as empresas estatais: uma contribuição ao debate sobre a Reforma do Estado". Relatório de Pesquisa IESP n. 13, 1994.

Tosi Jr., H.; Gomez-Mesia, L. R. "The decoupling of CEO pay and performance: an agency theory perspective". Administrative Science Quarterly 34, 1989. 
Resumo

Resúmen

Abstract

\section{Contratos de gestão: instrumentos de ligação entre os setores do aparelho do Estado}

Marcelo de Matos Ramos

Este artigo visa desenvolver algumas questões sobre os contratos de gestão, e sobre o movimento pela "contratualização" tanto nas relações entre o Estado e o setor privado, quanto nas relações intra-estatais. A "contratualização" é então abordada desde duas tradições: uma é a tradição advinda da administração pública, que enfatiza aspectos relacionados à identidade, socialização, sistema de crenças e capacitação da burocracia pública; a outra corresponde à tradição disciplinar da economia, mais preocupada com os aspectos microeconômicos relativos à estrutura de incentivos com que se deparam os atores em uma organização burocrática. A experiência nacional e internacional em "contratualização" é brevemente analisada, e concluímos propondo algumas recomendações e indicando novos rumos de pesquisa.

Contratos de gestión: instrumentos de ligación entre los sectores del aparato del Estado

Marcelo de Matos Ramos

Esto artículo se propone a desarrollar algunas reflexiones sobre los Contratos de Gestión, tanto en las relaciones Estado-sector privado, como en las relaciones intraestatales. El artículo aborda la "contractualización" hacia dos tradiciones: una, con respecto a la administración pública, tiene su centro en los aspectos relacionados a la identidad, socialización, el sistema de creenzas y la capacitación de la burocracia pública; la otra, correspondiente a la tradición disciplinaria de la economía, atenta a los aspectos microeconómicos de la estructura de incentivos que encuentran los actores en las organizaciones burocráticas. La experiencia internacional y nacional es revista. El artículo termina con algunas recomendaciones y apunta nuevas direcciones de investigación.

\section{Management agreements: linking tool among State sectors}

Marcelo de Matos Ramos

This article aims to unfold some reflexions about the "contractualization" movement, both in state-private sector relationships and intra-state relationships. The article takes two approaches to "contratualization": one looks at the public administration tradition, what emphatizes the aspects linked to the training, development, socialization, identity and belief systems of the public bureaucracy; the other, more economizing one, is concerned with the microeconomic aspects related to the incentive structure facing actors in a bureaucratic organization. National and international experience in "contratualization" are reviewed and the article concludes proposing some recomendations and pointing to new research directions. 